TRANS · núm. $24 \cdot 2020$

MISCELÁNEA $\cdot 245-262$
Este artículo se basa en los resultados obtenidos del análisis de los expedientes de censura de las novelas traducidas al catalán, publicadas a lo largo de los años sesenta, en el marco de la tesis doctoral «La censura franquista i la traducció catalana de narrativa als anys seixanta». Tras seleccionar las obras traducidas a lo largo de la década, hemos construido un corpus que nos ha permitido investigar de forma exhaustiva las repercusiones de la censura sobre la traducción catalana durante ese periodo. Mediante el examen de los informes conservados en el Archivo General de la Administración (AGA) y la lectura comparativa de los originales - o galeradas-y las versiones definitivas correspondientes, hemos reunido un conjunto de datos con el que pretendemos demostrar dicho control.

PALABRAS CLAVE: censura, franquismo, traducción catalana, narrativa, años sesenta.

\title{
Los efectos de la censura franquista sobre la traducción catalana de narrativa en los años sesenta: una perspectiva panorámica
}

\section{LARA ESTANY FREIRE}

Universitat Autònoma de Barcelona

\section{The Effects of Franco's Censorship on the Catalan Translation of Narrative during the Sixties: a panoramic perspective}

This article is based on the results obtained from the analysis of the censorship files of the novels translated into Catalan, published throughout the sixties, within the framework of the doctoral thesis "La censura franquista i la traducció catalana de narrativa als anys seixanta». After selecting the translated works throughout the decade, we have built a corpus that has allowed us to investigate exhaustively the repercussions of censorship on Catalan translation during that period. By examining the reports kept in the Archivo General de la Administración (AGA) and the comparative reading of the originals - or galley proofs - and the corresponding final versions, we have gathered a set of data with which we intend to demonstrate such control.

KEY WORDS: censorship, francoism, Catalan translation, narrative, the 1960s. 


\section{1. ANTECEDENTES}

La Guerra Civil española interrumpió la continuidad de la tradición editorial mediante la represión política y, sobre todo, la implantación de la censura. Al acabar el conflicto, las lenguas minoritarias - y minorizadas - del territorio fueron relegadas de la vida pública y la traducción de obras foráneas a dichas lenguas se convirtió en una actividad prohibida, considerada incluso ilícita. En este sentido, las directrices del Régimen se mantuvieron firmes y, en pocos años, el libro catalán se convirtió en un simple objeto de coleccionista que llegaba a una parte muy escasa de la población, gracias a la edición clandestina y a unos escasos tirajes de bibliófilo.

Desde el principio, los sublevados pusieron en marcha una serie de mecanismos muy bien planificados, con el fin de mantener a la población alejada de la cultura, sumisa y dócil, y preparar el terreno que les permitiría introducir la doctrina del Movimiento Nacional. Esta estrategia les funcionó durante los primeros años de la postguerra, si bien en el año 1945 la derrota nazi-fascista en la Segunda Guerra Mundial forzó al franquismo a minimizar los referentes que lo vinculaban al fascismo y a acentuar la imagen de un régimen católico autoritario (Santacana, 2000: 26). Cuando el sector falangista se vio obligado a traspasar el poder a los sectores católicos, el impulso y la vehemencia de los primeros tiempos perdieron fuerza y los profesionales del libro, fuertemente controlados, pudieron por fin reemprender la actividad editorial. De todas formas, los ideales persistieron, dado que era imprescindible conservar una sola lengua que dominara a las otras lenguas del Estado. Uno de los efectos secundarios de esta política fue que en catalán solo se autorizaron algunas expresiones culturales y folclóricas, siempre que fueran consideradas puramente locales. Con un con- trol exhaustivo sobre la producción autóctona, la literatura catalana sufrió las consecuencias de una vigilancia obsesiva por parte de las autoridades y, hasta principios de los años cincuenta, fue casi imposible publicar de forma legal (Bacardí y Godayol, 2017: 129). Muchos escritores tuvieron que adaptarse, en contra de su voluntad, a unas circunstancias desfavorables (sobre todo, si formaban parte del registro de «rojos y desafectos»). Si de aquella época apenas quedan obras inéditas es porque se imprimían en el exilio o en la clandestinidad, o porque muchos intelectuales dejaron de escribir. Así pues, el efecto más nocivo de la represión cultural y lingüística no fue que se censuraran los textos o que se quedaran sin publicar, sino que se destruyera el sistema literario (Cornellà-Detrell 2017: 129).

Por otro lado, es importante recordar que las repercusiones de la práctica censora no solo perjudicaron a escritores y editores (y otros profesionales de los distintos campos de la cultura), sino que también damnificaron al público lector. Tal como argumenta Fernando Larraz, en realidad hablamos de uno de los numerosos derechos que fueron sustraídos a la sociedad como resultado del triunfo franquista: «el de poder leer obras clásicas, autores contemporáneos extranjeros o, sencillamente, [...] disponer de escritores que cumplieran con su función social» (2014: 39). La pervivencia de la actividad literaria fue posible gracias a la resistencia y a la perseverancia de personas que, a pesar de las condiciones adversas, siguieron trabajando, escribiendo y editando. En aquellos tiempos de penuria, muchos escritores catalanes tuvieron que recurrir a la traducción al castellano como trabajo subsidiario, dado que sus obras (si escribían) no tenían cabida en el mercado editorial. De hecho, el refugio de la traducción fue posible gracias a la concienciación, y a veces al mecenazgo, de algunos editores (Bacardí, 2012: 21). 
A pesar de que el franquismo ostentó una organización ejemplar desde sus inicios, los cambios - internos y externos - que se fueron produciendo a lo largo de los años cuarenta y cincuenta lo forzaron a adaptarse. Y la censura, igualmente, fue evolucionando a medida que el Régimen redefinía sus prioridades (CornellàDetrell, 2012: 27-28). En definitiva, la censura que se había ejecutado durante el primer período, bajo el dominio del sector falangista (que anhelaba la creación de un estado autoritario fascista), dio paso a otra censura, no menos represiva, pero supeditada al mantenimiento de unos valores ultraconservadores.

Las reformas sociales e institucionales que se llevaron a cabo a principios de los años sesenta, entre otros motivos, por la inestabilidad económica que había propiciado el aislamiento del Estado, sacudieron las bases de la censura, favorecieron la recuperación de la traducción catalana y, de paso, fomentaron la recuperación gradual de la lengua en el campo de la cultura. En estas circunstancias, muchos editores empezaron a incorporar obras extranjeras en sus catálogos, de manera que no solo impulsaron el enriquecimiento del fondo editorial — por entonces muy debilitado-, sino que también promovieron la entrada de la literatura y el pensamiento contemporáneos. La situación de euforia que se vivía a causa de las reformas políticas animó a algunas editoriales a crear colecciones formadas exclusivamente - o casi- por obras extranjeras. Así, tras más de veinte años de restricciones, al inicio de la década la traducción catalana experimentó un crecimiento sin precedentes.

\section{SITUACIÓN POLÍTICO-CULTURAL EN LA DÉCADA DE 1960}

A finales de los años cincuenta y a principios de los sesenta se hizo evidente el fracaso de los ideales falangistas de la primera postguerra, dado que la estructura de medidas represivas que el Régimen había aplicado durante más de veinte años tenía cada vez más detractores. La inestabilidad económica, junto con la presión internacional y la mala reputación de la censura a aquellas alturas exigieron un cambio de estrategia. En 1962 Manuel Fraga Iribarne fue nombrado responsable del Ministerio de Información y Turismo (MIT) y se convirtió en uno de los principales representantes del «sector reformista» del Régimen. Esta tendencia propugnaba pequeñas reformas institucionales, con el fin de adecuarlo a aquello que los cambios económicos y sociales exigían: el Estado abrió las puertas al turismo, las costumbres extranjeras y la economía exterior. Se trataba de una estrategia política que daba un aire de modernidad sin cambiar, en realidad, la esencia del Régimen.

Este giro aperturista acarreó una época excepcional en la historia de la traducción catalana, durante la cual se empezaron a traducir títulos que hasta entonces habían sido prohibidos. Dicha «traducción intensiva» supuso un impulso incontestable, que revitalizó a los profesionales relacionados con el mundo del libro: escritores que se convertían en traductores, editores que lanzaban colecciones para introducir un número ingente de títulos extranjeros, autores que se dedicaban a sus propias obras... Todo ello confluyó en una atmósfera de optimismo y de dinamismo, cuyo resultado no tardó mucho en hacerse visible. A mediados de los años sesenta, el peso de la traducción había crecido tanto que el número de obras traducidas ya superaba el de las obras autóctonas, tal como muestra esta tabla, elaborada con datos proporcionados por Francesc Vallverdú (1975: 106): 
Tabla 1. Francesc Vallverdú ${ }^{1}$

\begin{tabular}{cccc}
\hline Año & $\begin{array}{c}\text { Número total de libros } \\
\text { publicados en catalán }\end{array}$ & Número de obras traducidas & $\begin{array}{c}\text { Porcentaje de traducciones } \\
\text { respecto al total publicado }\end{array}$ \\
\hline 1960 & 183 & 10 & $5.50 \%$ \\
\hline 1962 & 270 & 49 & $18.20 \%$ \\
\hline 1963 & 309 & 131 & $42.40 \%$ \\
\hline 1964 & 368 & 186 & $50.50 \%$ \\
\hline 1965 & 430 & 236 & $54.90 \%$ \\
\hline 1966 & 548 & 207 & $37.80 \%$ \\
\hline 1967 & 469 & 171 & $36.46 \%$ \\
\hline 1968 & 460 & 143 & $31.08 \%$ \\
\hline 1969 & 393 & 113 & $28.75 \%$ \\
\hline
\end{tabular}

En solo media década, el porcentaje de traducciones respecto al total de obras publicadas experimentó un salto espectacular: mientras que en 1960 se publicó un total de 183 libros en catalán, de los cuales solo diez eran traducciones, en 1965, de los 430 libros publicados, 236 eran traducciones; es decir, se pasó de un $5,5 \%$ de traducciones a un $54,9 \%$. El salto fue más pronunciado al principio de la década — sobre todo de 1962 a 1963-y más moderado posteriormente. El aumento de más del 50\% hacia 1965, punto de máximo esplendor, es indicador de dos hechos inherentes: en primer lugar, la censura, que había suavizado las medidas restrictivas aplicadas a la traducción, dejó de percibirla como una actividad nociva e ilícita; y, en segundo lugar, la asimilación del pensamiento extranjero como propio ya era, en efecto, una realidad.

A pesar de haber ampliado un poco los límites, a lo largo de la década la censura continuó fun-

I El trabajo de Francesc Vallverdú no incluye las cifras de 1961. cionando bajo los mismos criterios. El filtraje de tipo ideológico, doctrinal, religioso y moral —en definitiva, el filtraje político- al que debían ser sometidos todos los textos estaba regulado por un cuestionario, que ya había sido establecido en 1946, y que facilitaba la labor de los censores a la hora de determinar si los textos cumplían el dogma básico o si, por el contrario, vulneraban algunos puntos: «1) ¿Ataca al dogma?, 2) ¿a la moral?, 3) ¿a la Iglesia o a sus ministros?, 4) ¿al régimen y a sus instituciones?, 5) ¿a las personas que colaboran o han colaborado con el régimen? [...]» (Abellán, 1980: 19).

En definitiva, los criterios esenciales que debían acatar los funcionarios fueron sintetizados por Manuel Abellán en 1980 (88-89):

a. Moral sexual entendida como prohibición de la libertad de expresión que implicara, de alguna manera, un atentado al pudor y a las buenas costumbres en todo lo relacionado con el sexto mandamiento y, en estrecha unión con dicha moral, abstención de referencias al aborto, homosexualidad y divorcio. 
b. Opiniones políticas.

c. Uso de lenguaje considerado indecoroso, provocativo e impropio de los buenos modales por los que se ha de regir la conducta de las personas que se autodefinen como decentes.

d. La religión como institución y jerarquía, depositaria de todos los valores divinos y humanos e inspiradora de la conducta humana arquetípica.

Cualquier texto sospechoso de transgredir alguno de estos preceptos se prohibía o mutilaba automáticamente. Aun así, el veredicto a menudo dependía de las opiniones o de los intereses de los funcionarios, de modo que el criterio, muchas veces, era subjetivo y arbitrario. Una de las novedades de aquella época fue la incorporación de nuevos géneros, inéditos en catalán, que propició la creación de nuevos catálogos. El caso más evidente es el de la novela policíaca o, como había empezado a llamarse desde hacía algún tiempo en Francia, la novela negra. La Cua de Palla (de Edicions 62) se convirtió en la colección pionera en catalán de dicho género e inspiró a otras editoriales, como Aymà, que estrenó la serie Enjòlit, o Molino, que lanzó la colección Interrogant.

No obstante, dejando a un lado las dificultades, es importante subrayar que el libro catalán, por primera vez en muchos años, era visto como un objeto comercial y que, en efecto, se había pasado de una cultura de resistencia a una cultura que aspiraba a una cierta regularidad (Bacardí, 2012: 51). Basta tener en cuenta que casi trescientas novelas extranjeras pudieron ser publicadas en catalán a lo largo de la década.

\subsection{La autocensura como práctica profesional autocoercitiva}

En 1995 Estanislau Torres consignó tres niveles en «la escala de la censura»: la del propio autor; la de los responsables de las editoriales, las revistas y los periódicos, y la de los que «tenían la última palabra» (1995: 55). A inicios de la década de los sesenta, en un evidente estado de temor e incertidumbre, la autocensura ejecutada por los escritores y traductores responde a la necesidad de hacer frente al aparato represor implantado por la dictadura; de evitar, en definitiva, las pugnas y conflictos que comportaba el hecho de presentar una obra que pudiera ser motivo de controversia. Aun así, no todos los casos de autocensura se definieron por el esfuerzo del escritor - o del traductor - de suprimir pasajes o modelar los textos en función de los gustos de los censores (autocensura explícita). Según Manuel L. Abellán, la idiosincrasia de algunos profesionales marcó la práctica de la escritura y la traducción, dado que en estos casos existía un hábito intencionado o un condicionante histórico (autocensura implícita) (1982: 171). De este modo, las convicciones morales de algunos intelectuales los llevaron a utilizar expresiones «inocuas» y a suavizar o mitigar ciertas proposiciones, e incluso a rechazar la traducción de obras que consideraban indecorosas. En cualquier caso, el uso reiterado de la autocensura, que se generalizó tanto «como consecuencia de la larga duración del régimen franquista» (Larraz, 2014: 33), dio lugar a muchos textos suavizados y «preparados» para ser aceptados por la censura.

Los editores también cumplieron una función fundamental: eran los encargados de dictar las pautas sobre el funcionamiento de las empresas $\mathrm{y}$, en última instancia, los máximos responsables de las publicaciones. Así, pues, eran los encargados de seleccionar las obras y, por consiguiente, los autores. Dejando a un lado las políticas oficiales de la censura, las de cada editorial también determinaban qué obras se debían incorporar a los catálogos. El nombre de un escritor a veces era motivo suficiente para rechazar un escrito, 
250

aunque el contenido no atentara contra la moral (lo cual no solo afectó a autores contrarios al Régimen, sino que también perjudicó a los que se declaraban afines). Resulta evidente que tanto editores como directores literarios optaron por la cautela - sobre todo desde el establecimiento de la Ley de Prensa e Imprenta- y que muchas de las instancias que emitieron a la Sección de Inspección de Libros —o, desde 1963, a la Sección de Orientación Bibliográfica- se limitaron a obras deliberadamente «inofensivas», según los cánones franquistas

Hasta qué punto la autocensura determinó la creación literaria y la manipulación de las obras originales - en el caso de la traducción- es una cuestión muy difícil de valorar, si no imposible, teniendo en cuenta que se trata de una práctica mucho más intangible que la perpetrada por la administración, la cual, al fin y al cabo, ha quedado registrada en incontables informes y galeradas subrayadas.

\subsection{La implantación de la Ley de Prensa e Imprenta}

El 18 de marzo de 1966 Fraga Iribarne impulsó la Ley de Prensa e Imprenta, también conocida como la Ley Fraga, que sustituía la del 29 de abril de 1938 y que, teóricamente, atenuaba la censura previa de cualquier tipo de publicación editorial y periodística. Esta propuesta permitió una cierta ampliación de la libertad de información en libros, periódicos y revistas, aunque todavía presentaba importantes restricciones: a partir de ese momento ya no se censuraba, sino que se «aconsejaba» el sometimiento de los textos a la llamada «consulta voluntaria». Debe considerarse este cambio como una estrategia que el gobierno usó para mitigar la mala reputación de la censura, que no ayudaba al proyecto "reformis- ta" del régimen; puede contemplarse, también, como «un subterfugio que Fraga y su cuñado Robles Piquer consideraban un progreso liberal» (Morán, 2014: 624).

El aparente liberalismo de la nueva ley provocó que los editores vigilaran con más rigor los escritos que presentaban, y a menudo mediante la autocensura de los manuscritos con el fin de evitar posibles sanciones. Dado que se mantenían las normas y los criterios de censura previa, los preceptos debían ser igualmente respetados. De hecho, este era el principal temor de los editores, pues la retirada de un tiraje completo en circulación podía suponer una pérdida económica en muchos casos devastadora. Si bien algunos editores se arriesgaron a no presentar las obras a censura y las entregaron directamente a depósito, la mayoría prefirió someterse a la consulta voluntaria: en cualquier momento, la Junta de Censura podía requisar los ejemplares publicados que no habían sido revisados.

\section{LA CENSURA EN LA NOVELA TRADUCIDA AL CATALÁN}

Una de las principales cuestiones que nos planteamos al iniciar el estudio hace referencia al alcance de la censura franquista en la recuperación de la traducción catalana: ¿Hasta qué punto afectó la represión del MIT a la publicación de traducciones a lo largo de la década? Independientemente de los resultados del análisis de los expedientes del AGA, de todas las obras mutiladas, de las que fueron prohibidas, o de las que fueron autorizadas íntegras, podemos corroborar, dada la información ya existente sobre el funcionamiento de la censura, que alteró toda la producción escrita; como también es incontestable que el fondo editorial habría sido distinto sin este organismo de control. 
En nuestro trabajo, seleccionamos un total de doscientas noventa y nueve novelas ${ }^{2}$, descartando todas aquellas que ya habían sido traducidas anteriormente (es decir, las que eran reediciones) y las que, a pesar de haberse traducido por primera vez en la década de los sesenta, fueron publicadas a partir del año 1970. Tras examinar los expedientes de censura y llevar a cabo las lecturas comparativas correspondientes descubrimos que, si bien el volumen de traducciones autorizadas con supresiones finalmente no fue demasiado elevado (42), comparado con el número total de obras analizadas $(288)^{3}$, los porcentajes de las novelas que sufrían un destino $\mathrm{u}$ otro variaron cada año, en función de la conjuntura política o administrativa. Dado que la narrativa es un campo tan heterogéneo, los censores se vieron obligados a afrontar diversos escenarios y a permanecer atentos a posibles «amenazas», como las imágenes o alegorías que suelen usar los autores. Resulta evidente, después de observar los numerosos expedientes, que muchas veces las resoluciones se definieron por la subjetividad, lo cual provocó que a menudo los trámites se prolongaran más allá de los límites razonables (las resoluciones se emitían al cabo de unos cuantos días o semanas, si bien a veces podían tardar años).

Esta arbitrariedad se manifiesta, por ejemplo, en los veredictos de las novelas de la serie James Bond, de Ian Fleming, que se empezaron a traducir al castellano y al catalán durante los años sesenta. A pesar de que la mayoría fueron mutiladas (debido al contenido erótico, e incluso político), hubo otros casos en los que se publicaron

2 Aunque tratamos de construir un inventario exhaustivo, es posible que involuntariamente omitiéramos algún título durante el proceso.

3 En el AGA localizamos los expedientes de doscientas ochenta y ocho novelas; los once títulos restantes no han sido incluidos en el estudio. íntegras. Las obras de Fleming sirven también para evidenciar el papel más bien secundario que desempeñaban los lectores (generalmente, responsables de efectuar las primeras lecturas y de redactar los informes). En realidad, los encargados de alto rango, es decir, el Jefe de la Sección de Orientación Bibliográfica y el Director General de Información, no siempre usaban las indicaciones de los lectores como elemento decisivo, por lo que a veces era necesaria una serie de negociaciones dentro de la organización del Ministerio para alcanzar una decisión unánime, circunstancia que contribuía al mencionado retraso burocrático. Es el caso de la novela Diamants eterns (Diamonds Are Forever, 1956), cuya traducción pasó el filtro de la censura sin supresiones. El padre Saturnino Álvarez Turienzo, prolífico y acreditado censor religioso desde 1951 (Sopena, 2013: 149-150) ${ }^{4}$, fue el encargado de redactar el informe el 1 de junio de 1965: «El gran escritor Ian Fleming, presenta en esta novela, otro de sus éxitos en las series de aventuras, acción, ritmo trepidante etc., que tanto éxito vienen teniendo en los libros y en la pantalla cinematográfica» ${ }^{5}$. A pesar del prestigio de Álvarez Turienzo, la superioridad pidió una segunda opinión al padre Miguel Oromí, probablemente para asegurarse que no habían sido omitidos los pasajes de moral «dudosa» que abundaban en las obras de Fleming. Así, el 23 de junio Oromí emitió un segundo veredicto que simplemente corroboraba el del primer censor: «Se trata de una novela policíaca con DOS ROMBOS.- No veo inconveniente en que pueda publicarse ${ }^{6}$. La novela fue autorizada definitivamente el $2 \mathrm{de}$ julio e incorporada a la colección Enjòlit en 1966.

4 Considerado un «censor de prestigio», fue un miembro eminente de la orden agustiniana, especializado en obras filosóficas y «autoridad incontestable a ojos del MIT».

5 AGA, SC, expediente 3811, caja 21/16266.

6 Ibidem. 
252 Aunque en este caso los trámites se llevaron a cabo con rapidez, hubo novelas que no tuvieron tanta suerte. El 28 de setiembre de 1965 Ricard Domènech, en representación de Aymà, mandó una instancia a la administración para solicitar el permiso de Una espia a la casa de l'amor (A Spy in the House of Love, 1954), de Anaïs Nin. La obra, que todavía no había sido publicada en castellano, iba acompañada, como era habitual, de un ejemplar de la versión original. El primer informe, del 17 de octubre, concluyente, decretó su prohibición dado que, según el lector, vulneraba la moral sexual de forma escandalosa:

(C) Novela inmoral. Prototipo del libro er[ó]tico. $\mathrm{El}$ argumento es una mujer casada que engaña a su marido con el primero que se presenta. Va de amante en amante, describi[é]ndonos las reacciones y sensaciones que con cada uno de ellos experimenta. Los contactos sexuales son descritos con toda crudeza. El objetivo de la protagonista es llegar a ser verdaderamente libre; entendiendo por libertad el entregarse a los hombres sin que ning[ú]n sentimiento [la] ligue con [é]l. NO DEBE AUTORIZARSE SU PUBLICACI[Ó]N.?

En un segundo informe, del 9 de noviembre, el censor Santos González volvió a desaprobar la publicación. Los argumentos, un poco más indulgentes que los del primer lector, apelaban una vez más a la transgresión de la moral:

(C). Esta escritora norteamericana se encuentra en la línea, a veces tan obscura, de la literatura erótica de Henry Miller, con el que ha trabajado, y de Lawrence. En su novela hay tesis, hay una doctrina, por encima y más allá de lo anecdótico del personaje: una mujer casada que engaña a su marido con varios amantes. Un marido bueno, enamorado pero que no la hace feliz. Ella tampoco lo es porque está engañando, tiene que mentir y ocultarse para hacer esa vida.

7 AGA, SC, expediente 7088, caja 21/16626.
Esta mujer encuentra justificación en la novela, es más, está comenzando a andar por los campos del amor. Tendrá que liberarse de ciertos tabús: la culpa, el sacerdote, la policía. La mujer tiene diversas pautas amorosas y tiene derecho a desarrollarlas. El amor es evolución, desarrollo, cambio, no encerrarse en una forma s[o]la. «En Sabina hay muchas Sabinas que también reclaman vivir y amar». Más que alguna que otra escena escabrosa está esta doctrina disolvente, esta visión del amor moderno tan destructora. NO AUTORIZABLE. ${ }^{8}$

Los editores no se conformaron con esta resolución, por lo que diez días más tarde enviaron a la Junta de Censura un recurso de revisión. A continuación, referenciamos tres de las alegaciones por su relevancia:

[...] que la autora del libro en cuestión, es la señora Anaïs Nin, escritora en lengua inglesa, residente en los Estados Unidos y figura literaria de relieve internacional, nacida en Barcelona e hija del notable musicólogo español Joaquín Nin; compañera de Henry Miller, Lawrence Durrell y otros grandes escritores contemporáneos, sus novelas están obteniendo vivos elogios de la crítica más solvente y recientemente han sido traducidas al francés y al italiano. ${ }^{9}$

El segundo punto intentaba minimizar el carácter sexual de la obra, incidiendo en el estilo narrativo de la escritora:

[...] que los temas tratados por la autora se desarrollan en ámbitos difusos, intermedios entre la realidad y el sueño y poseen acentos poéticos que difuminan sus contornos, por lo que, pese a su ocasional sensualismo, sus vagas narraciones no resultan nunca escandalosas ni procaces. ${ }^{10}$

El tercero cuestionaba la conveniencia de rechazar a una autora como Anaïs Nin, con el riesgo que ello comportaba:

8 Ibidem.

9 Ibidem.

Io Ibidem. 
[...] que habiendo la señora Anaïs Nin mostrádose sumamente complacida por nuestro proyecto de editar alguna de sus obras en sus idiomas naturales —el castellano y el catalán-, estimaríamos harto lamentable que, a causa de la denegación recurrida, se viera la autora inclinada a ceder las instancias de sus editores en inglés, los cuales le aconsejan que conceda los derechos de publicación de sus obras en español a una determinada editorial sudamericana. ${ }^{11}$

En cuanto al último argumento, cabe mencionar que la situación de las empresas que editaban en castellano a finales de los años cincuenta y a principios de los sesenta era difícil, teniendo en cuenta que la política de censura que se practicaba en el Estado provocó indefectiblemente que muchos autores internacionales de prestigio, que no estaban dispuestos a ver recortadas sus obras, cedieran los derechos a otros países de habla hispana, sobre todo a Argentina y Méjico. Así pues, la presión del régimen sobre el sector editorial solo consiguió que las empresas españolas acabaran ocupando un segundo lugar, en detrimento de la competencia latinoamericana (Estany, 2019: 95).

La estrategia de los editores dio resultado, ya que al cabo de unas semanas la Junta emitió un dictamen, redactado el 24 de noviembre, que difería en gran medida de los anteriores:

(C). La obra me parece más simbólica que realística. Es la historia de una prostituta que no encuentra ni la felicidad ni el amor. Hay un ambiente de amoralidad que el autor no aprueba en realidad, situaciones y pensamientos atrevidos y sensuales pero a mi juicio no hay nada obscuro ni pornográfico.

Puede ser publicada pero ser[í]a conveniente que la versión española pasara por esta censura. ${ }^{12}$

II Ibidem.

I2 AGA, SC, expediente 7088, caja 21/16626. Aunque hace
La conclusión de este expediente pone en evidencia el hecho de que después del recurso los censores empezaron a buscar subterfugios para justificar la autorización de la obra. Por otra parte, puesto que no debía saber cómo resolver el problema, la superioridad optó por posponer la resolución definitiva a la presentación del texto traducido, «sobre el que se harán, si son necesarias, las oportunas indicaciones $»^{13}$. Por motivos que desconocemos, la editorial tardó casi tres años en presentar la traducción a censura. El 25 de abril de 1968 se abrió un nuevo expediente, esta vez sobre la versión de Manuel Carbonell. El mismo día se emitieron dos informes, la incongruencia de los cuales es casi inexplicable. El primero empleaba un tono severo e incluso acusaba a la novela de «delito de escándalo público»:

(C). Novela cuya protagonista, una mujer casada que ama a su marido, engaña a [é]ste buscando a diversos hombres con los que satisfacer sus ansias eróticas de posesión y de los que obtener goces plenos sin entregarse anímicamente. Con este motivo la autora se dedica morosamente a describir las sensaciones que experimenta su protagonista en los diversos lances eróticos que le depara el azar y que ella busca voluntariamente.

Tanto el tema de la obra, como las descripciones que se ofrecen en las p[á]gs. 30, 59, 73, 74, 79, 81, 101 y $102,108,112$ y 113,120 y 121 entre otras muchas, implican la comisión de un delito de esc[á] ndalo público, previsto y penado en el art. 432 del Cod. penal, por lo que estimamos que la novela debe ser puesta a disposición del fiscal de la Audiencia provincial de Barcelona y que NO ES ACEPTABLE EL DEPÓSITO. ${ }^{14}$

referencia a una «versión española», ratificamos que se trata del expediente de la catalana. El error es debido, probablemente, a un descuido del censor.

${ }^{13}$ Ibidem.

${ }^{14}$ AGA, SC, expediente 3557, caja 21/18909. 
El segundo, también del 25 de abril, exponía una opinión bastante distinta:

Examinado rápidamente el texto de la novela «Une espionne dans la maison de l'amour» de Anaïs Nin [nótese que esta vez el lector ha usado la versión francesa para efectuar la lectura], se observa a primera vista su argumento netamente sensualizado (vid. p[á]gs. 32,44,59,69,70,96, 114, 115, 119 etc.) en la descripción de las sensaciones que una mujer casada (Sabine) tiene con diversos y sucesivos amantes que tiene (sic). La esencia del argumento es pues, desde un punto de vista moral católica estricta inmoral, puesto que se está ante una situación de adulterio continuado.

Sin embargo, y siendo justos, también hay que señalar que en la novela no se hacen descripciones que entren dentro de lo grosero, lo puerco o lo estrictamente pornográfico. La sensualidad prima sobre la sexualidad. Con independencia de que no se trata, desde luego, de una novela para jovencitas ni mucho menos, desde el punto de vista del Ministerio nos parece que no se trata de un folleto obsceno, aunque si inmoral. Desde este punto de vista de ausencia de materia pornográfica, podría ser aceptable en régimen de depósito. ${ }^{15}$

El dictamen definitivo que emitió el censor Antonio Barbadillo — posiblemente, en calidad de Jefe de Lectorado- sirve para capitular todo este periplo administrativo:

Despu[é]s de una serie de informes algo contradictorios, con fecha 16 de Diciembre de 1965, se solicitaba a la editoral Aymá texto traducido. Contenido inmoral, de un crudo realismo, que repugna la sensibilidad media de nuestra sociedad; rehuyéndose la obscenidad, que es elemento que matiza y caracteriza a la pornografía. Descripción elegante, a veces casi poética, por parte de la autora.

Como consecuencia de una interpretación Jurídica, estimo que no se da la figura delictiva de

15 Ibidem. escándalo público, prevista en el artículo 431 del Código Penal. La única figura delictiva [que] podemos considerar infringida es la del artículo 156 bis [apartado] b) del $\mathrm{m}[\mathrm{i}]$ smo Cuerpo Legal, por la publicación de informaciones peligrosas para la moral o las buenas costumbres.

Desde este punto de vista, y partiendo de una interpretación estrictamente Jurídica, cabría la posibilidad de hacer uso de la facultad concedida a la Administración por el artículo 64 de la vigente Ley de Prensa e Imprenta; pero, en consideración de las circunstancias que concurren en el expediente que nos ocupa, estimo preferible no impedir la libre difusión de la publicación; o en último caso, para mayor seguridad efectuar denuncia particular al Ministerio Fiscal, con remisión de un ejemplar, para el supuesto de que considerase la existencia de alguna figura delictiva. ${ }^{16}$

Así, la acusación de delito de escándalo público fue desestimada. En abril de 1968, al no saber cómo debía proceder, la Junta de Censura optó por ampararse en el «silencio administrativo». ${ }^{17}$ A pesar del riesgo que comportaba, la editorial ignoró las advertencias de los censores y el mismo año publicó la novela íntegra en la prestigiosa colección A Tot Vent.

\subsection{Primer periodo (1959-1963)}

Los primeros años, los del «arranque», se tramitaron pocas instancias de autorización: en

${ }^{16}$ Ibidem.

${ }^{17}$ El silencio administrativo fue un recurso utilizado con frecuencia por los censores durante el periodo de vigencia de la Ley de Prensa e Imprenta, que representaba la aceptación tácita de las obras. Constituía una forma de resolver los expedientes «conflictivos» que, o bien no sabían cómo resolver, o bien comportaban un riesgo de negligencia en caso de dictar un veredicto «erróneo». Evidentemente, las repercusiones de un procedimiento tan inestable no beneficiaban a los editores, dado que la falta de una aprobación explícita y oficial por parte de la administración implicaba el peligro de cometer un delito y de ser sometidos a nuevos procesos judiciales y a la requisa de ejemplares. 
1959 se emitieron dos solicitudes que fueron aprobadas sin supresiones; las tres que se enviaron en 1960 también se resolvieron de la misma forma; de las ocho novelas que se presentaron en 1961, siete fueron publicadas íntegras y una obtuvo el consentimiento con cortes $;^{18}$ y de las tres que se iniciaron en 1962, una fue primeramente denegada y después autorizada y dos se editaron intactas. A pesar de que solo hubo una obra censurada, principalmente por motivos políticos y religiosos, los informes elaborados a lo largo de ese periodo nos permiten determinar que la lengua todavía era uno de los criterios que los censores tenían en cuenta, así como la moral sexual.

El año 1963, no obstante, después del punto de inflexión que significó la entrada de Manuel Fraga Iribarne al Ministerio, fue otro momento decisivo que, desde entonces, transformó la actuación de la censura ante la traducción catalana. Entre los motivos que provocaron este cambio podemos destacar el aumento significativo de peticiones que las editoriales emitieron ese año a censura (la mayoría, de Edicions 62): treinta y siete. Por otra parte, el examen de los expedientes también nos ha llevado a inferir que, dejando de lado la subjetividad de los censores, que explica la aleatoriedad ya mencionada, debía de haber otros factores que influían en las decisiones, sobre todo, de la superioridad. Nos referimos a los pactos o tratos de favor, muchas veces negociados en actos extraoficiales (celebraciones, banquetes, eventos deportivos...), que no han quedado registrados en los dossiers del AGA y que explicarían algunos cambios de opinión incongruentes.

La mayor parte de las obras que los editores enviaron a censura en 1963 fueron autorizadas sin supresiones (34), una fue denegada y posteriormente autorizada, y dos se aprobaron censu-

I8 Déu ha nascut a l'exili (Dieu est né en exil, 1960), de Vintilă Horia. radas. ${ }^{19}$ En cuanto a los criterios de censura, persistieron, más o menos, los mismos de los años anteriores: la obra de Sébastien Japrisot fue mutilada por motivos de moral sexual, y la de James Joyce, por supuestos ataques a la religión.

\subsection{Segundo periodo (1964-1965)}

El impulso que había tomado el sector editorial en 1963 prosiguió, de modo que en 1964 ya se autorizaron setenta y nueve novelas, y en 1965 , setenta y ocho. Todo indica que los editores a aquellas alturas ya habían perdido ciertos temores, hasta el punto de que a veces no tenían tiempo suficiente para publicar los títulos que habían sido autorizados, y por este motivo tuvieron que incluirlos en sus catálogos los años siguientes. Una muestra de esta circunstancia es el aumento del porcentaje de traducciones con respecto al total de obras publicadas en 1964 (50,50\%), que fue, según Vallverdú, un hecho coyuntural (Llobet, 2012: 403), y que prosperó en 1965 (54,9\%).

Del total de novelas que se presentaron a censura en 1964, sesenta y dos fueron autorizadas íntegras, dos fueron prohibidas y posteriormente aprobadas y dieciséis fueron mutiladas ${ }^{20}$. En

I9 Parany per a una noia (Piège pour Cendrillon, 1963), de Sébastien Japrisot; Retrat de l'artista adolescent (A Portrait of the Artist as a Young Man, 1916), de James Joyce. Si bien en la obra de Joyce el lector marcó numerosos fragmentos obscenos, la traducción «se mantuvo fiel al original», a excepción de un eufemismo utilizado para suavizar una expresión malsonante.

${ }^{20}$ Jim i la sort (Lucky Jim, 1954), de Kingsley Amis, que, como en el caso anterior, a pesar de la sugerencia del MIT, fue traducida literalmente, hasta el punto de mantener el sentido sexual a lo largo de la obra; El caos i la nit (Le chaos et la nuit, 1963), de Henry de Montherlant; La camperola (La ciociara, 1957), de Alberto Moravia; El diable als turons (Il diavolo sulle colline, 1948), de Cesare Pavese; Des de Rússia amb amor (From Russia with Love, 1957), de Ian Fleming; La truita (La truite, 1964), de Roger Vailland; El carter sempre truca dues vegades (The Postman Always Rings Twice, 1934), de James M. Cain; La modificación (La Modification, 1957), de Michel Bu- 
cuanto a los criterios de censura, predominaron los relacionados con la moral sexual y la política, lo cual no nos sorprende, teniendo en cuenta que los autores de cuatro de las obras censuradas eran italianos, abiertamente comunistas. En este sentido, es importante destacar la solicitud de Aymà para El bell estiu (La bella estate, 1949), de Cesare Pavese, dado que, en el informe, aunque favorable, aparece la primera mención al editor italiano Giulio Einaudi:

«La bella estate», - (El bello verano) es una novela sentimental que transc[u]rre en una ciudad italiana. El personaje principal, una joven de 17 años, - se enamora de un pintor y en el espacio de un verano hace sus planes que en realidad son sueños de amor. [...]

La obra no tiene nada de particular. Mencionamos que ha sido publicada en italiano por Einaudi. PUEDE AUTORIZARSE. ${ }^{21}$

El porcentaje de obras censuradas más o menos se mantuvo en 1965. De las setenta y ocho novelas, sesenta y tres recibieron el consentimiento sin supresiones, seis fueron inicialmen-

tor; Dissabte a la nit $i$ diumenge al matí (Saturday Night and Sunday Morning, 1959), de Alan Sillitoe; El cor és un caçador solitari (The Heart is a Lonely Hunter, 1940), de Carson McCullers; Els afers del senyor Juli Cèsar (Die Geschäfte des Herrn Julius Caesar, 1957), de Bertolt Brecht; El penjat de Saint-Pholien (Le pendu de Saint-Pholien, 1931), de Georges Simenon; Els nus $i$ els morts (The Naked and the Dead, 1948), de Norman Mailer; Color de sang (The Red Scarf, 1958), de Gil Brewer; El baró rampant (Il barone rampante, 1957), de Italo Calvino; El company (Il compagno, 1947), de Cesare Pavese.

${ }^{21}$ AGA, SC, expediente 5421, caja 21/15495. En 1962 Einaudi fue el encargado de publicar en Italia la antología de protesta Canti della nuova resistenza spagnolla (1939-1961). Como consecuencia sobre todo de este proyecto, fue declarado persona non grata por el franquismo y se le prohibió la entrada a España. Además, mantuvo relaciones personales con el editor Carlos Barral y otros intelectuales españoles, con los que compartía una ideología política filocomunista (y, por supuesto, el rechazo al fascismo). te prohibidas y después autorizadas, y nueve fueron mutiladas. ${ }^{22}$ Los motivos de la censura seguían encabezados por la moral —la sexual, sobre todo-, seguidos de los criterios que se regían por la religión y la política: el año 1965 estuvo condicionado por la presentación de muchas obras de Ian Fleming y, en general, del género policíaco.

Asimismo, cabe remarcar que la lectura de los expedientes pone de manifiesto que en aquel periodo de esplendor el MIT hizo todo lo posible para conceder autorizaciones, a veces mediante resoluciones inexplicables. A fin de cuentas, el objetivo del régimen era continuar ofreciendo una imagen de apertura y progreso al exterior, y evitar las críticas de la prensa internacional (que, indefectiblemente, comportaría la censura de escritores contemporáneos reconocidos y de prestigio).

\subsection{Tercer periodo (1966-1969)}

En 1966 el número de peticiones se redujo considerablemente, ya que solo se presentaron treinta y una. Una de las causas del declive fue, aparte de la inminente crisis editorial ${ }^{23}$, que ya

${ }^{22}$ Cuatro novelas de Ian Fleming: Dr. No (Dr. No, 1958), Viure $i$ deixar morir (Live and Let Die, 1954), Operació tromba (Thunderball, 1961) y Al servei secret de sa majestat (On Her Majesty's Secret Service, 1963); Una vida violenta (Una vita violenta, 1959), de Pier Paolo Pasolini; En mans de l'F.B.I. (Case File: FBI, 1953), de Mildred Gordon; La mort de William Posters (The Death of William Posters, 1965), de Alan Sillitoe; Cap de turc (The Mob Says Murder, 1959), de Albert Conroy; Un diable al paradís (A Devil in Paradise, 1956), de Henry Miller.

${ }^{23}$ La inserción repentina de un volumen tan elevado de títulos en un campo cultural en aquellos momentos devastado topó con algunos obstáculos. El esfuerzo de los editores, por más intenso que fuera, no podía ser suficiente para conseguir que los lectores se adaptaran sin contratiempos al ritmo frenético que marcaba la industria cultural; si bien es cierto que a corto plazo los resultados fueron excepcionales, a la larga se hizo evidente que existía un desequilibrio con- 
empezaba a percibirse, la confusión generada por la implantación de la Ley Fraga. Veintinueve obras fueron autorizadas íntegras, una fue inicialmente denegada y después autorizada y otra fue aprobada con supresiones ${ }^{24}$, por causa de moral sexual y de lenguaje inapropiado.

En los años 1967 y 1968 los efectos del giro administrativo se empezaron a hacer evidentes: aunque el número de tramitaciones continuó disminuyendo (probablemente a causa de los recursos cada vez más escasos que los editores destinaban a las traducciones), los porcentajes de obras mutiladas fueron muy elevados. De las veintitrés solicitudes que se presentaron en 1967 , catorce se resolvieron sin supresiones, una fue primero vetada y después autorizada y ocho se tramitaron con supresiones ${ }^{25}$. Esta cifra representaba un $35 \%$ de las peticiones totales. Sobre

siderable entre el volumen de producción y la demanda real. Aún faltaban algunos elementos esenciales para alcanzar la recuperación definitiva de la cultura catalana: la regularización del uso de la lengua en todos los ámbitos, la base de la enseñanza, el apoyo institucional y la repercusión de la prensa. Además, a aquellas alturas ya no era posible cubrir los gastos elevadísimos que ocasionaba la incorporación de tantas traducciones a los catálogos. Por otra parte, el giro administrativo que se desencadenó durante los últimos años del franquismo condicionó enormemente el desarrollo de la crisis. En aquellos momentos, la política aperturista de Fraga Iribarne no tenía demasiada popularidad dentro del régimen y se inició un periodo de retroceso. La posición del ministro era cada vez más precaria, hasta que en octubre de 1969 fue destituido y sustituido por el político ultraconservador Alfredo Sánchez Bella (Estany, 2019: 542-543).

${ }^{24}$ Meinard Stam, ara difunt (Gun Before Butter, 1963), de Nicolas Freeling.

${ }^{25}$ L'any 1919 (1919, 1932), de John Dos Passos; El punt dolç de la senyoreta Brodie (Prime of Miss Jean Brodie, 1961), de Muriel Spark; El gat i la rata (Katz und Maus, 1961), de Günter Grass; Darrera la porta (Dietro la porta, 1964), de Giorgio Bassani; Senyoreta Corsolitari (Miss Lonelyhearts, 1933), de Nathanael West; A cadascú el que és seu (A ciascuno il suo, 1966), de Leonardo Sciascia; El ritual de la sang (Lady, Lady I Did It!, 1961), de Ed McBain; Aparadors per a una dona (The Company She Keeps, 1942), de Mary McCarthy. los criterios de censura, podemos decir que la moral sexual fue, de nuevo, el predominante, que en dos casos se censuraron pasajes por motivos políticos y que dos obras fueron censuradas por contener blasfemias y atentar contra la religión. También hemos observado que en 1967 se empezaron a emitir solicitudes de depósito directamente, ya que hacía algún tiempo que se había establecido la nueva ley y los editores, a pesar del riesgo que implicaba, empezaron a publicar los libros antes de haber obtenido la aprobación del MIT. Aun así, solo lo hicieron en los casos que sabían que no les comportaría una pérdida económica: solamente en cuatro ocasiones.

En 1968 se gestionaron los trámites de dieciséis novelas, de las cuales once fueron aceptadas sin supresiones y cinco obtuvieron el consentimiento con restricciones $(31 \%)^{26}$. Los criterios de los censores se centraron en las causas habituales, esta vez de forma más equitativa: moral sexual, política, religión y lenguaje «indecente». Por lo que respecta a las solicitudes de depósito, solo se emitieron dos: la mayoría de las obras se sometieron a la censura previa. Uno de los expedientes paradigmáticos tramitados ese año es el de Trenta mil pessetes per un home (Treinta mil pesetas por un hombre, 1968), de Francisco Candel. La instancia, emitida el 4 de enero por Alfaguara, iba acompañada de la galerada de la traducción. Dada la fama contestataria de Candel y el contenido de la obra, el primer veredicto no resultó del todo favorable; aunque autorizaba la publicación, el número de pasajes censurados era desorbitante:

${ }^{26}$ Trenta mil pessetes per un home (Treinta mil pesetas por un hombre, 1968), de Francisco Candel; Trucada per al mort (Call for the Dead, 1961), de John Le Carré; Enquesta (Inquest, 1960), de Milton K. Ozaka; El salari de la por (Le salaire de la peur, 1950), de Georges Arnaud; Retrat en fum (Portrait in Smoke, 1950), de Bill Balinger. 
(C). Conjunto de narraciones, casi todas ellas en la tesis corriente ya en Candel de pretender la denuncia de los males sociales y de describir la vida de los barrios menesterosos, o las hipocresías de católicos indignos, todo ello siempre recargando las tintas en un afán de aguafuerte más que goyesco.

Algunos de sus cuentos pasan ya de la ray[a] de lo indecoroso para llegar a lo totalmente indecente, como los titulados «Ja em voldr[i]a morir!» (p[á] g. 13 a 16), «Fes un pet[ó] al Sant Crist!» (p[á]g. 18 a 22), «El drap» (p[á]g. 22 a 28); otros son denigrantes para el ejército como «La fusila» (p[á]g. 28 a 32); caricaturescos o gr[o]tescamente menospreciadores de frailes españoles, como «Fray Gerundio de Campazas» (p[á]g. 60 a 87), o con tendencia a denigrar al Régimen como «L'home que s'escrivia amb Franco» (p[á]gs. 122 a 140), que son totalmente impublicables y deben ser eliminados. En los dem[á]s deben de eliminarse las frases señaladas a 1[á]piz rojo [en] las p[á]gs. 8, 9, 146, y asimismo las p[á]gs. todas de 175 a 177 ambas inclusive por indecorosas. Con estas eliminaciones puede autorizarse ${ }^{27}$

El Jefe de Sección no debió de quedar muy convencido, de modo que pidió a otro lector que elaborara un segundo informe:

Serie de cuentos, de diversa extensión y temática. Los hay evidentemente inspirados en la vida corriente; otros, en cambio, son alegóricos. El conjunto parece pintar aspectos de la sociedad, las personas y las costumbres con una mezcla de sátira y de intención sociológica crítica. Son pinceladas vigorosas, llenas de ingenio y de buen arte literario, pero, por desgracia, abundan episodios blasfemos e inmorales. También los hay de clara intención política, con personajes blandos ante el marxismo y razonamientos que quieren justificarlo; resulta improcedente mezclar en un cuento el nombre de «Franco», que le da título y del que se abusa a lo largo de las páginas del mismo.

${ }^{27}$ AGA, SC, expediente 1104, caja 21/18737.
Se proponen las tachaduras siguientes: págs. 7, 15, 18-22 (cuento blasfemo y obsceno), 26, 27-28, 63, $64,67,68,69,70,72,84,122,124,125,126,130,132$, 133 bis, 135, 136, 137, 139, 140, 146, 149, 177 у 178 (este último cambiando el título del cuento, que es equívoco). Con las supresiones citadas, PUEDE AUTORIZARSE el libro. ${ }^{28}$

El resultado, como es evidente, no había cambiado demasiado. En una nota escrita al margen del documento, el Jefe de Sección rectificó la sentencia. No satisfecho con las treinta y dos páginas indicadas por lector, enumeró cuarenta y cinco (descartó dos páginas, pero añadió otras quince):

a. Supresi[ó]n de narraciones:

«Fes un pet[ó] al Sant Crist» (18 a 22)

«El drap» (22 a 28)

«La fusila» (28 a 32)

«L'home que s'escrivia amb Franco» (122-140)

b. Tachaduras p[á]gs. 15-63-64-67-68-69-7072-84-146-177 y $178 .^{29}$

Conforme con este último veredicto, el 9 de marzo el Director General envió un oficio a la editorial, indicando les numerosísimas páginas que contenían supresiones. Es relevante el hecho de que, aparte de una copia de la carta, el sobre del AGA incluye otra misiva que desaconsejaba la edición de la obra. Ignoramos si también llegó a los editores, o si sencillamente la prepararon por si finalmente decidían emitir una denegación; en cualquier caso, Alfaguara devolvió la galerada «retocada» al cabo de unos meses, junto con unas anotaciones ${ }^{30}$. El 23

28 Ibidem.

29 Ibidem.

30 Ibidem. A continuación referenciamos las «notas con relación a lo censurado: 18 a 22 - se devuelve al autor SE QUITA; 122 a 140 - se eliminan los términos y p[á]rrafos marcados; 15 - se elimina lo marcado; 63 - id.; 64 - El autor no cede: opina que es inofensivo, por demás ingenuo, el párrafo «Por qué permite tener al Santo Cristo desnudo en la iglesia?[»] [la su- 
de agosto recibió la siguiente valoración:

Después del ejemplar devuelto por la editorial con supresiones y anotaciones, y vistos los informes anteriores, al ser examinado nuevamente el original a mi juicio la situaci[ó]n definitiva es la siguiente:

Las supresiones indicadas son: págs 8-9-15-18 a 22-22 a 28-32-63-67-68-69-70-72-132-133-133bis 135-136-137-140-145-146-177 y 178. Como se ve se han suprimido dos relatos completos «Fes un petó al Sant Crist» por ser francamente irreverente, y «El drap» porque es inmoral y sobre todo sucio y de mal gusto.

En cambio el relato «El hombre que se escrib[í]a con Franco», puede subsistir con este título. No es necesario cambiar en todos los lugares del relato la palabra Franco por Felip, ya que con las supresiones indicadas el relato queda pasable. ${ }^{31}$

Tres días más tarde, el 26 de agosto, un lector distinto redactó un informe anexo, que complementaba al anterior:

Tras las enmiendas introducidas y que aparecen verificadas a 1[á]piz rojo, puede aceptarse la narración que figura bajo el t[í]tulo «L'home que s'escrivia amb Franco» aún dejando permanecer el nombre de «Franco» que me parece más indicado que el cambiado como se propone, por «Felipe», ya que en aqu[é]1 no se produce ninguna falta de respeto, y en cambio con el de «Felipe» se trasluce o se deja traslucir una intervención de censura oficial nada oportuna.

perioridad se muestra conforme]; 67 - se elimina; 68 -id.; 69 -id.; 70 - id.; 72 - id.; 84 - «Qué coño era esto...[»] Este coño forma parte entrañable del lenguaje del personaje [conforme]; 146 - La copla es popular en cierto nivel, casi honda; hay que dejarla como expresión de una determinada psicología social; 177 - No atenta contra nada. Es cuestión de lenguaje [conforme]; 178 - Se ha modificado el título como se sugería».

3I Ibidem.
La copla que se deniega en la p[á]g. 146 debe seguir siendo suprimida por lo torpe y grosero de la misma, sobre todo si se tiene en cuenta que se entremezcla con villancicos. En cuanto al resto de la obra pueden aceptarse las modificaciones propuestas, a pesar del mal gusto de las [ú]ltimas frases del pen[ú]ltimo y [ú]ltimo p[á]rrafos de la p[á]g. 177.32

Así pues, el 3 de septiembre la dirección volvió a contactar con la editorial para comunicarle la respuesta siguiente:

En contestación a su consulta de fecha 7 de febrero de 1968 relativa a la obra TREINTA MIL PESSETES PER UN HOME [...] se aconseja la supresión de los pasajes señalados en las páginas 22 a 28-32-132133-bis-135-136-137-139-140. Sin supresión de los t[é]rminos «FRANCO Y CAUDILLO» y 146.- (así como 18 a 22$).{ }^{33}$

Es decir, finalmente, después de tantas mediaciones, «solo» se censuraron veinte páginas. El 21 de diciembre Jorge Cela Trulock, en representación de la editorial ${ }^{34}$, hizo efectivo el depósito de ejemplares, que fue corroborado por el Jefe de Sección el 9 de enero de 1969: «Comprobadas y conformes las tachaduras» ${ }^{35}$. En 1968 la obra de Candel, mutilada, se publicó en la colección Ara i Ací.

En 1969 solo se iniciaron seis trámites, todos de depósito, que se resolvieron, en todos los ca-

32 Ibidem.

33 Ibidem. A pesar de que finalmente se permitió el uso de los nombres «Caudillo» y «Franco», hubo otros que tuvieron que ser modificados, como el de «Antonio Carnerero Blanco», que fue sustituido por «Antonio Carrasco Valdés». A modo de ejemplo, referenciamos uno de los fragmentos censurados: «Tot d'una, algú cantà una cançó abstracta, no de Nadal. —A tu padre le he visto la tomatera; a tu madre el tomate, y a tíla pera».

${ }^{34}$ Hermano de Camilo José Cela, que era el director de Alfaguara.

35 AGA, SC, expediente 1104, caja 21/18737. 
sos, con un consentimiento sin supresiones. Tal vez la naturaleza de las obras, que mayoritariamente habían sido escritas por autores cercanos al régimen, tuvo algo que ver con ello ${ }^{36}$.

\section{CONCLUSIONES}

A lo largo de este estudio hemos tenido la oportunidad de analizar numerosos expedientes de censura, así como de examinar los textos de las traducciones mutiladas y confrontarlos con las versiones que finalmente fueron publicadas. En este caso, tal como Jordi Jané-Lligé argumenta, es importante determinar qué alteraciones llevadas a cabo en relación con los textos originales (supresiones, modificaciones, cambios de estilo...) son imputables a la acción directa de la censura y cuáles responden a otros condicionantes no vinculados a la actuación censora (2013: 120). Tras realizar una observación sistemática de los expedientes, podemos concluir que la autocensura tuvo bastante más incidencia sobre la producción literaria que la censura, ya que los circunloquios y los eufemismos fueron recursos muy utilizados, no solo de forma preventiva, sino también posteriormente, a la hora de ejecutar las correcciones indicadas por la dirección. Encontramos un ejemplo en el veredicto que emitió el censor Mampel sobre Els nus i els morts, de Norman Mailer, traducida por Ramon Folch i Camarasa, después de que el traductor ya hubiera mitigado el texto: «Algunas expresiones se han suavizado al traducir la novela al catalán. Pero quedan todavía como inadmisibles las señaladas en las páginas $[\ldots] \gg^{37}$.

${ }^{6}$ Els xiprers creuen en Déu (Los cipreses creen en Dios, 1953), Un milió de morts (Un millón de muertos, 1961), Ha esclatat la pau (Ha estallado la paz, 1966), de Josep M. Gironella; El rusc (La colmena, 1951), de Camilo José Cela; Morin els capellans (Muerte a los curas, 1968), del sacerdote José Luis Martín Vigil.

37 AGA, SC, expediente 5695, caja 21/15529.
Algunos censores intervinieron reiteradamente en los procesos de las novelas traducidas al catalán. Es el caso del padre - y erudito- Saturnino Álvarez Turienzo, que ejerció de lector especialista (como el juez Francisco Fernández Jardón, el padre Miguel Oromí o el padre Francisco Aguirre), e influyó particularmente en segundos informes de numerosos expedientes. Fue monje agustino y profesor de la Universidad de Salamanca; es evidente que en sus informes demostró una erudición y amplitud de miras poco habitual entre los censores (Jané-Lligé 2013: 123). No obstante, su «autoridad incontestable» en el Ministerio fue puesta en entredicho en una ocasión: en 1965 autorizó sin supresiones la obra de Ian Fleming Diamants eterns («El gran escritor Ian Fleming, presenta en esta novela, otro de sus éxitos en las series de aventuras[...] que tanto éxito vienen teniendo en los libros y en la pantalla cinematográfica») ${ }^{38}$, pero el veredicto tuvo que ser corroborado por Miguel Oromí («Se trata de una novela policíaca con DOS ROMBOS.- No veo inconveniente en que pueda publicarse») ${ }^{39}$.

Vale la pena remarcar la gran capacidad de algunos censores de sintetizar las obras o de analizarlas minuciosamente, como Mampel (siempre firmaba bajo ese pseudónimo), que en 1967 realizó un examen excepcionalmente riguroso de Fonatamara (Fontamara, 1930), de Ignazio Silone, mediante el que decretaba su prohibición por hacer una apología del comunismo que, a su juicio, era intolerable. De hecho, Mampel, que redactó varios veredictos, sobre todo en los últimos años de la década, siempre usaba expresiones censorias, a diferencia de Álvarez Turienzo. Según Mireia Sopena, sus informes tendían a

\footnotetext{
$3^{8}$ AGA, SC, expediente 3811, caja 21/16266.

39 Ibidem.
} 
posiciones restrictivas y, aun así, sus dictámenes nunca tuvieron la fuerza de voces tan autorizadas como las del censor religioso o Fernández Jardón (2013: 157).

Por otra parte, la intervención de las editoriales fue esencial en el desarrollo de la industria literaria. A pesar de que nos hemos centrado en el ámbito de la narrativa, y que no hemos tenido en cuenta el gran volumen de solicitudes que también se presentaron a censura para obras de otros géneros, las cifras son sorprendentes: un total de veinticuatro editoriales pusieron sus recursos al servicio de la recuperación de la cultura. No obstante, las dificultades fueron constantes, como hemos visto: trámites interminables e, incluso, denuncias judiciales (Una espia a la casa de l'amor, Anaïs Nin, exp. 3357/68). Sería conveniente realizar un estudio de todas las peticiones de ficción traducida emitidas en los sesenta -incluidas las que fueron autorizadas y publicadas más allá del año 1969 y las que fueron denegadas - para poder hacer un balance más exacto de la implicación de todas las editoriales en ese periodo. Asimismo, disponemos de datos suficientes para corroborar que los editores llevaron a cabo una labor extraordinaria, y que, a través de la elaboración de sus catálogos y asumiendo a veces enormes riesgos, se vieron obligados a estimular la creatividad a fin de encontrar los pequeños resquicios que les permitirían, al fin, introducir discursos críticos y renovadores de autores y obras extranjeras en la España franquista (Jané-Lligé 2013: 120).

El análisis de los expedientes de censura y el examen de los fragmentos mutilados en las obras narrativas nos han permitido construir una visión panorámica de lo que significó la censura para el sector editorial en la década de 1960 y, más concretamente, para la traducción catalana. Naturalmente, esta perspectiva podría ser ampliada mediante el estudio de otros factores también relevantes: las posibles razones por las que las editoriales escogieron cada obra, sus rasgos estilísticos o la recepción que tuvieron (Cornellà-Detrell 2012: 46). También sería importante tener en cuenta las distintas reediciones o retraducciones de las obras que no se publicaron íntegramente a fin de entender el alcance real del control ejercido por el régimen. De hecho, la censura es una de las herencias olvidadas del franquismo, que se ha continuado reproduciendo más allá del fin de la dictadura (CornellàDetrell 2010: 48). Esta línea de investigación permitiría dar visibilidad, de una vez por todas, a este «legado invisible» de la dictadura.

\section{REFERENCIAS BIBLIOGRÁFICAS}

Abellán, Manuel L. (1980): Censura y creación literaria en España (1939-1976), Barcelona: Península.

Abellán, Manuel L. (1982): «Censura y autocensura en la producción literaria española», Nuevo Hispanismo, 1, 169-180.

ARBonĖs, Jordi (1995): «La censura sobre les traduccions a l'època franquista», Revista de Catalunya, 97, 87-96.

BACARDí, Montserrat (2012): La traducció catalana sota el franquisme, Lleida: Punctum.

BACARDí, Montserrat; GodAYol, Pilar (2017): Traducció $i$ franquisme, Lleida: Punctum.

Bassnett, Susan; Lefevere, André (1990): Translation, History and Culture, Londres: Pinter Publishers.

CAstellet, Josep M. (1987): «Memòries poc formals d'un director literari», en Edicions 62. Vint-i-cinc anys (1962-1987), Barcelona, 23-105.

Cisquella, Georgina; Erviti, José L.; Sorolla, José A. (2002): La represión cultural en el franquismo. Diez años de censura de libros durante la Ley de Prensa (1966-1976), Barcelona: Anagrama.

ColL-Vinent, Sílvia; EISNer, Cornèlia; GalLÉn, Enric (ed.) (2011): La traducció i el món editorial de postguerra, Lleida: Punctum.

Cornellà-Detrell, Jordi (2010): «Traducció i censura 
262 en la represa cultural dels anys 1960», L'Avenç, 359, 44-51.

Cornellà-Detrell, Jordi (2012): «La censura després dels censors: algunes reflexions sobre aspectes no resolts de l'herència cultural del franquisme», Anuari Trilcat, 2, 27-47.

Cornellà-Detrell, Jordi (2013): «L'auge de la traducció en llengua catalana als anys 60: el desglaç de la censura, el XVI Congreso Internacional de Editores i el problema dels drets d'autor», Quaderns. Revista de Traducció, 20, 47-67.

Cornellà-Detrell, Jordi (2017): «Estratègies contra la censura durant el període democràtic» en Montserrat Bacardí y Pilar Godayol (ed.), Traducció $i$ franquisme, Lleida: Punctum, 121-138.

Estany, Lara (2019): La censura franquista i la traducció catalana de narrativa als anys seixanta, Tesis doctoral, Barcelona: Universitat Autònoma de Barcelona.

GALlofré, Maria J. (1991): L'edició catalana i la censura franquista (1939-1951), Barcelona: Publicacions de l'Abadia de Montserrat.

JANÉ-Lligé, Jordi (2013): «Narrativa alemanya de postguerra: autors traduïts i censura», Quaderns. Revista de Traducció, 20, 117-145.

Larraz, Fernando (2014): Letricidio español. Censura y novela durante el franquismo, Gijón: Trea.

Lefevere, André (1992): Translation, Rewriting, and the Manipulation of Literary Fame, Londres: Routledge.

Llanas, Manuel (2007): Sis segles d'edició a Catalunya, Vic: Eumo.

Llobet, Alexis (2012): «Entrevista a Francesc Vallverdú», Quaderns. Revista de Traducció, 19, 397410.

Morán, Gregorio (2014): El cura y los mandarines (Historia no oficial del bosque de los letrados. Cultura y política en España, 1962-1966), Madrid: Akal.

Ruiz BAutisTA, Eduardo (coord.) (2008): Tiempo de censura. La represión editorial durante el franquismo, Gijón: Trea.

SANTACANA, Carles (2000): El franquisme i els catalans: els informes del Consejo Nacional del Movimiento: 1962-1971, Catarroja: Afers.

Sopena, Mireia (2013): «"Con vigilante espíritu crítico”. Els censors en les traduccions assagístiques
d'Edicions 62», Quaderns. Revista de Traducció, 20, 147-161.

Sopena, Mireia (2015): «Los satélites de la curia diocesana. Censores eclesiásticos en la Barcelona de los sesenta», en Enric Gallén (dir.), «La censura franquista y la literatura y la cultura en lengua catalana», Represura, 1, 66-92.

ToRres, Estanislau (1995): Les tisores de la censura, Lleida: Pagès.

VALLVERDÚ, Francesc (1975): L'escriptor català i el problema de la llengua, Barcelona: Edicions 62.

VAlLVERdú, Francesc (1987): «Cinquanta anys de l'edició en català (1936-1986)», en Edicions 62. Vint- $i$-cinc anys (1962-1987), Barcelona: Edicions 62, 111-118.

Van Den Hout-Huijben, Lidwina M. (2015): El rojo crítico. Expansión de la literatura catalana bajo censura (1962-1977), Tesis doctoral, Groningen: Rijksuniversiteit Groningen.

Vila-SAnjuÁn, Sergio (2003): Pasando página: autores y editores de la España democrática, Barcelona: Destino.

VILARDELl, Laura (2016): Traducció $i$ censura en el franquisme, Barcelona: Publicacions de l'Abadia de Montserrat. 